\title{
Repetition priming in task switching: Do the benefits dissipate?
}

\author{
ERIK M. ALTMANN \\ Michigan State University, East Lansing, Michigan
}

\begin{abstract}
In task-switching research, one process that has been implicated as a possible source of switch cost is repetition priming. In four experiments, an examination was made of the claim that repetition priming dissipates over the interval between trials and thereby causes switch cost to decrease with increases in the response-cue interval (RCI). In Experiments 1 and 2, RCI was manipulated within participants, producing the standard RCI effect on switch cost. In Experiments 3 and 4, RCI was manipulated between participants and had no effect on switch cost. The role of experimental design and the mixed pattern of effects on switch and repeat trials in Experiments 1 and 2 suggest that a passive architectural process such as priming dissipation is not responsible for the RCI effect on switch cost. Repetition priming may still be responsible for some or all of switch cost, but it appears to be more stable over time than was previously thought.
\end{abstract}

In studies of task switching, distinctions have been made between processes that actively prepare the cognitive system to perform the current task and processes that reflect a more passive influence carried forward from the previous trial (Dreisbach, Haider, \& Kluwe, 2002; Koch, 2001; Meiran, Chorev, \& Sapir, 2000; Sohn \& Anderson, 2001, 2003). In one common paradigm, for example, participants are presented with a sequence of stimuli, and before each stimulus they are presented with a task cue indicating how to interpret that stimulus and map it to a response. (A single stimulus might map to different responses, depending on the cue.) By comparing performance on repeat trials (on which the task cue repeats from the preceding trial) with performance on switch trials (on which the task cue differs from that of the preceding trial), one can measure the cost of switching from one task to another. By varying the interval between cue onset and stimulus onset - the cue-stimulus interval, or CSI - one can measure the time course of processes that respond actively to the task cue in preparation for performance of the indicated task. By varying the interval between the response on one trial and cue onset on the next trial-the response-cue interval, or RCI-one can measure the time course of processes that are more "passive," in the sense that they operate without knowledge of the upcoming task. Empirically, switch cost often decreases as RCI increases. The effect can be small (Logan $\&$ Bundesen, 2003) and qualified by circumstances (Luria \& Meiran, 2003; Meiran, Levine, Meiran, \& Henik, 2000),

\footnotetext{
The author thanks Iring Koch, Nachshon Meiran, and an anonymous reviewer for their comments and suggestions for improvement of the manuscript. Correspondence concerning this article should be addressed to E. M. Altmann, Department of Psychology, Michigan State University, East Lansing, MI 48824 (e-mail: ema@msu.edu).
}

but it has proven robust enough to be the basis of a theoretical interpretation: Repetition priming facilitates performance on the current trial when the same task was performed on the previous trial, with this priming decaying or dissipating over the interval between trials (Meiran, Chorev, \& Sapir, 2000; Sohn \& Anderson, 2001). There are other lines of evidence for repetition priming in task switching - for example, those from cue validity (Dreisbach etal., 2002) and sequence learning (Koch, 2001, 2005) studies - but the argument based on priming dissipation (Meiran, Chorev, \& Sapir, 2000; Sohn \& Anderson, 2001) was the first to be published and has perhaps attained the widest currency.

This study revisits the priming dissipation assumption, for two reasons. First, there are mixed results as to whether time really does moderate repetition effects (see, e.g., Keele, 1969). Moreover, some task switching studies show priming effects that persist for minutes (Allport \& Wylie, 2000; Waszak, Hommel, \& Allport, 2003), and repetition priming itself can last for days (see, e.g., BuckGengler \& Healy, 2001). Thus, there are various indications that repetition priming might be more stable than the dissipation hypothesis suggests.

Second, previous methodological research suggests the possibility that an unforeseen factor could be at work - namely, design of the RCI manipulation. Withinparticipants manipulations are popular for their statistical power, but exposure to one level of an independent variable can alter performance at another level, in such a way that the system responds to neither one in isolation but to the two in combination (see, e.g., Poulton, 1982). Indeed, recent work in task switching has shown that the "basic phenomenon" of the preparation effect (Monsell, 2003), in which switch cost decreases as CSI increases, is not so basic after all, seeming to vanish when CSI is manipulated between participants (Altmann, 2004a, 
2004b; Koch, 2001). Current evidence on the effect of RCI on switch cost comes largely from within-participants manipulations. There is one exception (Koch, 2001), but it seems important to ask if this outcome replicates and, if not, to examine potentially relevant differences between paradigms.

The questions, then, are twofold. First, how general are the effects attributed to priming dissipation in previous studies (Meiran, Chorev, \& Sapir, 2000; Sohn \& Anderson, 2001)? If the cause is really a passive architectural process such as priming dissipation, its effects should be evident in a wide variety of task-switching paradigms, including the explicit cuing paradigm used here. Second, is the design of the RCI manipulation a moderating factor? If the RCI effect on switch cost is due to priming dissipation, it seems unlikely that experimental design should play a role, given that priming processes are not among those typically viewed as susceptible to carryover effects from exposure to multiple levels of an independent variable.

\section{EXPERIMENTS}

In Experiments 1 and 2, RCI was manipulated within participants in an attempt to replicate the RCI effect on switch cost reported in previous studies (Meiran, Chorev, \& Sapir, 2000; Sohn \& Anderson, 2001). In both experiments, the explicit-cuing paradigm outlined above was used, with a task cue preceding every trial; RCI was either 100 or $800 \mathrm{msec}$ in Experiment 1 and either 100 or $1,600 \mathrm{msec}$ in Experiment2. Experiments 3 and 4 mirror Experiments 1 and 2, respectively, but RCI was manipulated between rather than within participants. (One might imagine that a within-participants blocked design would be preferable to a between-participants design because of its improved statistical power, but even blocked designs suffer from within-participants carryover effects; Altmann, 2004b.)

In terms of independent variables, the questions above focus on the presence or absence of an $R C I \times$ continuity interaction, in which the variable of continuity distinguishes between switch and repeat trials. As a preview of the results, the interaction is present in Experiments 1 and 2 but not in Experiments 3 and 4, suggesting that effects previously attributed to priming dissipation are due to some other process that is under strategic control, in such a way that this process can be affected by differences in the number of levels of RCI to which the system is exposed.

\section{Method}

Participants. Students from the Michigan State University psychology subject pool participated in exchange for course credit. Experiment 1 involved 30 participants, Experiment 2 involved 20, Experiment 3 involved 52, and Experiment 4 involved 38. Participants were replaced if their accuracy fell below $90 \%$, the level at which they were asked (through feedback after each block) to be more accurate (see below).
Materials. The task cue was either the letter " $\mathrm{h}$ " (meaning height) or the letter "w" (meaning width) presented in white in 40-point Monaco font in the center of a dark computer display. The trial stimulus consisted of one of four rectangles formed by factorially combining vertical and horizontal dimensions of $2.5 \mathrm{~cm}$ and $5 \mathrm{~cm}$, drawn in gray with a 5-pixel pen, also in the center of the display. The " $h$ " task was to judge the vertical height of the rectangle (tall or short), and the "w" task was to judge the horizontal width of the rectangle (thick or thin). The $\mathrm{Z}$ and / keys of a standard keyboard were used for both tasks. The response-to-key mapping was randomized between participants.

Procedure and Design. Each session began with an on-line introduction to the tasks and stimuli, followed by a practice block, with the experimenter present to answer any questions. The participants were told the total number of blocks and advised to take breaks between blocks if necessary.

Each trial began with a task cue presented for $100 \mathrm{msec}$, followed by a blank screen also lasting for $100 \mathrm{msec}$, followed, in turn, by stimulus onset and then a response. The task cue was chosen randomly on each trial, subject to the constraint that the same cue could not be selected on more than four trials in a row. The stimulus was also selected randomly, subject to the constraint that the stimulus from the previous trial could not be repeated on the current trial.

The participant's response to a trial was followed by an RCI and then the next task cue. The RCI was randomly selected on every trial in Experiments 1 and 2 and was constant for each participant in Experiments 3 and 4. The shorter RCI was $100 \mathrm{msec}$ in all the experiments. The longer RCI was $800 \mathrm{msec}$ in Experiments 1 and 3 and 1,600 msec in Experiments 2 and 4.

A session contained 25 blocks (including the practice block). In Experiments 1 and 3, a block consisted of 40 trials. In Experiment2, a block contained 30 trials, to accommodate the increase to a 1,600msec RCI on half of the trials. In Experiment 4, blocks in the 100msec RCI condition contained 40 trials and blocks in the 1,600msec RCI condition contained 20 trials, to roughly equate time per session across conditions. The participants received feedback after each block of trials. If they scored below $90 \%$, they were asked to be more accurate, and if they scored $100 \%$ they were asked to try to go faster.

The first four blocks and the first four trials of later blocks were excluded from analysis, as were trials on which the stimulus afforded the same response for both tasks (participants reported simply memorizing the response to these stimuli). ${ }^{1}$ Response time (RT) data were medians of correct trials following correct trials. An analysis of variance (ANOVA) with independent variables of RCI (100 vs. 800 or $1,600 \mathrm{msec}$ ) and continuity (switch vs. repeat) was applied to all four experiments; supplementary ANOVAs were applied to Experiments 1 and 2 to probe the RCI $\times$ continuity interaction found there, and cross-experiment ANOVAs are reported separately later.

\section{Results}

Experiment 1 (100- vs. 800-msec RCI, within participants). RTs for Experiment 1 appear in the top left panel of Figure 1. There were main effects of RCI $\left[F(1,29)=5.0, p<.04, \eta^{2}=.15\right]$, with RT for the 100 msec RCI $(832 \mathrm{msec})$ longer than that for the $800-\mathrm{msec}$ $\mathrm{RCI}(806 \mathrm{msec})$, and of continuity $[F(1,29)=45.8, p<$ $\left..001, \eta^{2}=.61\right]$, with RT for switch $(883 \mathrm{msec})$ longer than that for repeat $(754 \mathrm{msec})$. The $\mathrm{RCI} \times$ continuity interaction was reliable $\left[F(1,29)=7.1, p<.02, \eta^{2}=\right.$ $.20]$, with the $100-\mathrm{msec}$ RCI switch cost $(147 \mathrm{msec})$ greater than the $800-\mathrm{msec}$ RCI switch cost $(111 \mathrm{msec})$. In 
Experiment 1

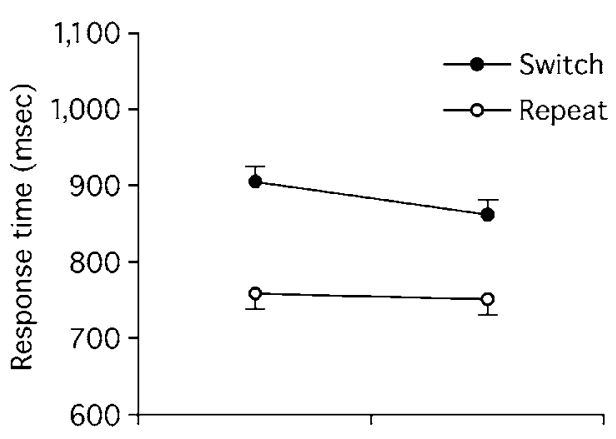

ㅎํํ

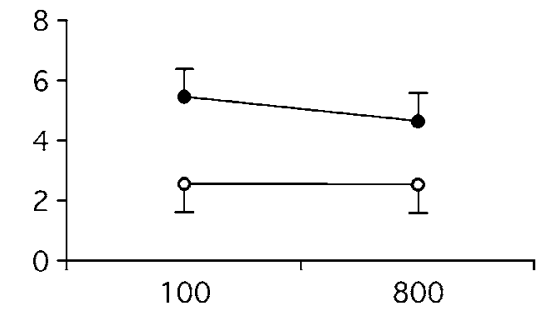

Response-cue interval (msec)

Experiment 2
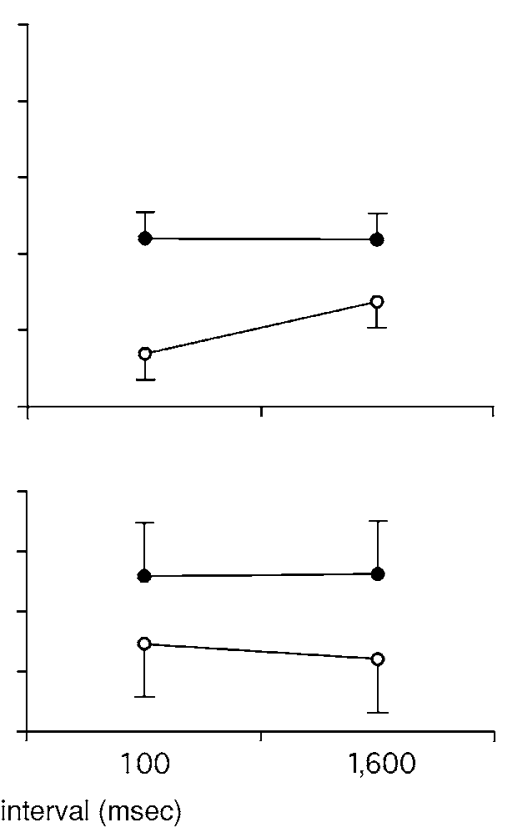

Figure 1. Response times and error percentages for Experiments 1 and 2, in which response-cue interval (RCI) was manipulated within participants. Error bars show 95\% confidence intervals computed with the error term of the RCI $\times$ continuity interaction (Loftus \& Masson, 1994, Equation 2, cited in Altmann, 2004a).

an examination of the interaction, the simple effect of RCI proved reliable on switch trials $[F(1,29)=8.8, p<$ $.007, \eta^{2}=.23$ ], with RT for the $100-\mathrm{msec} \mathrm{RCI}(905 \mathrm{msec})$ longer than that for the 800 -msec RCI ( $862 \mathrm{msec})$, but not on repeat trials $(F<1)$. Another ANOVA was conducted to probe sequential effects of RCI, in which the RCI-continuity factor distinguished between trials on which the RCI switched from the previous trial and trials on which it was repeated. There was no $\mathrm{RCI} \times$ continuity $\times$ RCI-continuity interaction $(F<1)$.

Error percentages appear in the bottom left panel of Figure 1. The main effect of RCI was not reliable $(p>$ $.12)$, but the effect of continuity was $[F(1,29)=17.7, p<$ $\left..001, \eta^{2}=.38\right]$, with switch errors $(5.05 \%)$ more frequent than repeat errors $(2.54 \% \mathrm{msec})$. There was no $\mathrm{RCI} \times$ continuity interaction $(p>.2)$.

Experiment 2 (100- vs. 1,600-msec RCI, within participants). RTs for Experiment 2 appear in the top right panel of Figure 1. The main effect of RCI was marginal $\left[F(1,19)=3.0, p=.098, \eta^{2}=.14\right]$, with $\mathrm{RT}$ for the 100 -msec RCI (745 msec) shorter than that for the 1,600msec RCI ( $778 \mathrm{msec})$. The main effect of continuity was reliable $\left[F(1,19)=14.7, p<.002, \eta^{2}=.44\right]$, with RT for switch $(819 \mathrm{msec})$ longer than that for repeat $(703 \mathrm{msec})$. The $\mathrm{RCI} \times$ continuity interaction was reliable $\left[F(1,19)=9.5, p<.007, \eta^{2}=.33\right]$, with the 100 msec RCI switch cost $(151 \mathrm{msec})$ greater than the 1,600msec RCI switch cost $(82 \mathrm{msec})$. An examination of the interaction revealed no simple effect of RCI on switch trials $(F<1)$, but there was one on repeat trials $[F(1,19)=$ $7.0, p<.02, \eta^{2}=.27$ ], with RT for the $100-\mathrm{msec} \mathrm{RCI}$ $(669 \mathrm{msec})$ shorter than that for the $1,600-\mathrm{msec} \mathrm{RCI}$ $(737 \mathrm{msec})$. There was again no $\mathrm{RCI} \times$ continuity $\times$ RCI-continuity interaction $(p>.3)$.

Error percentages appear in the bottom right panel of Figure 1. There was no main effect of RCI $(F<1)$, but continuity had a main effect $[F(1,19)=11.6, p<.004$, $\left.\eta^{2}=.38\right]$, with switch errors $(5.20 \%)$ more frequent than repeat errors $(2.66 \%)$. There was no $\mathrm{RCI} \times$ continuity interaction $(F<1)$.

Experiment 3 (100- vs. 800-msec RCI, between participants). RTs for Experiment 3 appear in the top left panel of Figure 2. There were main effects of RCI $\left[F(1,50)=9.9, p<.004, \eta^{2}=.17\right]$, with RT for the 100 msec RCI ( $874 \mathrm{msec})$ longer than that for the $800-\mathrm{msec}$ RCI $(730 \mathrm{msec})$, and continuity $[F(1,50)=51.7, p<$ $\left..001, \eta^{2}=.51\right]$, with RT for switch $(867 \mathrm{msec})$ longer than that for repeat $(737 \mathrm{msec})$. There was no RCI $\times$ continuity interaction $(F<1)$, with the $100-\mathrm{msec}$ RCI switch cost $(117 \mathrm{msec})$ actually trending smaller than the 800 -msec RCI switch cost (144 msec).

Error percentages appear in the bottom left panel of Figure 2. There was no main effect of RCI $(F<1)$, but continuity had a main effect $[F(1,50)=43.3, p<.001$, $\left.\eta^{2}=.46\right]$, with switch errors $(5.32 \%)$ more frequent than repeat errors $(3.23 \%)$. There was no $\mathrm{RCI} \times$ continuity 

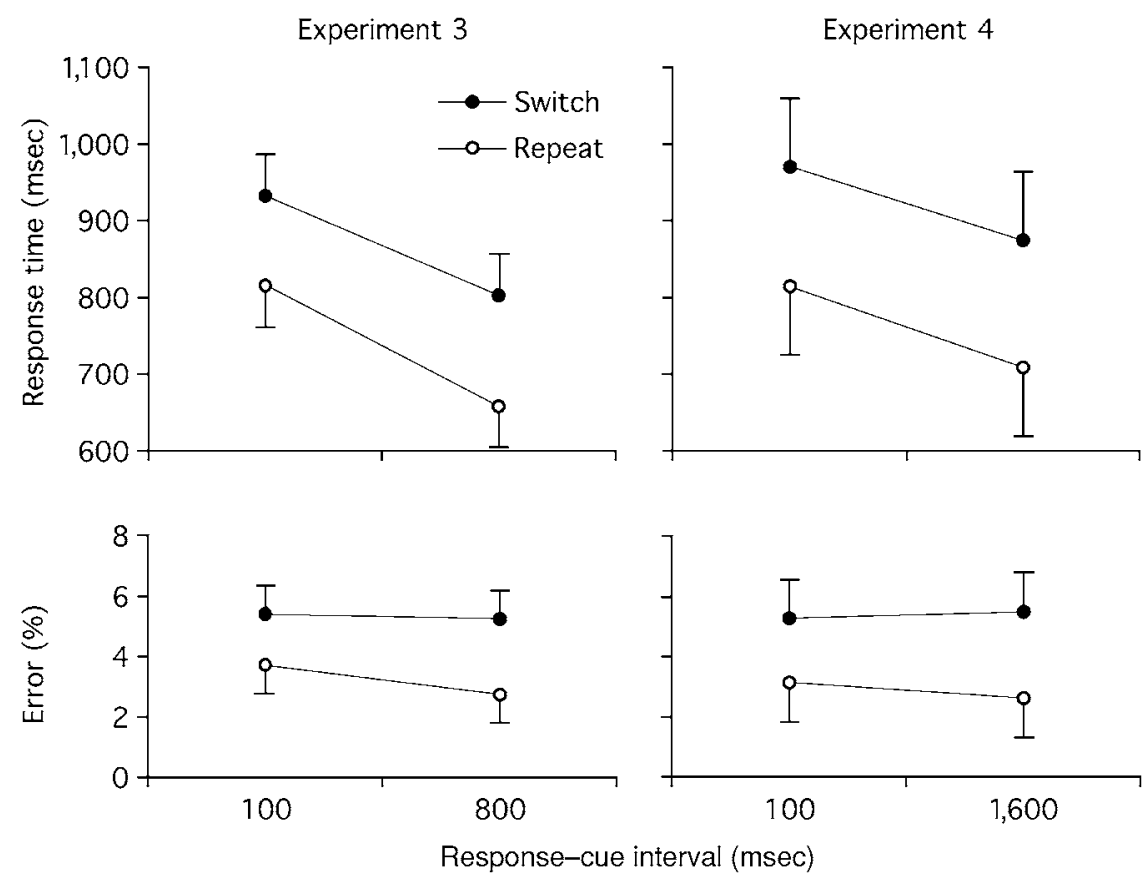

Figure 2. Response times and error percentages for Experiments 3 and 4, in which response-cue interval (RCI) was manipulated between participants. Error bars show $95 \%$ confidence intervals computed with the error term of the RCI $\times$ continuity interaction.

interaction $(p>.20)$, with the 100 -msec RCI switch cost (1.68\%) again trending smaller than the 800-msec RCI switch cost $(2.50 \%)$.

Experiment 4 (100- vs. 1,600-msec RCI, between participants). RTs for Experiment 4 appear in the top right panel of Figure 2. There was no effect of RCI $(p>$ $.12)$, but there was an effect of continuity $[F(1,36)=$ $\left.28.5, p<.001, \eta^{2}=.44\right]$, with RT for switch (922 msec) longer than that for repeat $(762 \mathrm{msec})$. There was no $\mathrm{RCI} \times$ continuity interaction $(F<1)$, with the 100 -msec RCI switch cost $(155 \mathrm{msec})$ trending smaller than the 1,600-msec RCI switch cost (166 msec), as in Experiment 3 .

Error percentages appear in the bottom right panel of Figure 2. There was no effect of RCI $(F<1)$, but continuity had an effect $\left[F(1,36)=32.4, p<.001, \eta^{2}=.47\right]$, with switch errors $(5.37 \%)$ more frequent than repeat errors $(2.88 \%)$. There was no $\mathrm{RCI} \times$ continuity interaction $(F<1)$, with the 100-msec RCI switch cost $(2.13 \%)$ again trending smaller than the 1,600-msec RCI switch cost $(2.86 \%)$.

\section{CROSS-EXPERIMENT ANALYSES}

The RCI $\times$ continuity interaction was reliable in Experiments 1 and 2, in which RCI was manipulated within participants, but not in Experiments 3 and 4, in which RCI was manipulated between participants. This suggests a role for experimental design in moderating the $\mathrm{RCI} \times$ continuity interaction, but only if one accepts the hypothesis of a null interaction in Experiments 3 and 4. Evidence favoring this null hypothesis is that the trend in these experiments is toward a reversal of the RCI $\times$ continuity interaction in Experiments 1 and 2, with switch cost actually slightly smaller in the longer RCI conditions than in the shorter RCI conditions.

To bolster the case, a cross-experiment ANOVA was conducted to test the $\mathrm{RCI} \times$ continuity $\times$ design (withinparticipants vs. between-participants) interaction, using Erlebacher's (1977) procedure for comparing withinand between-participants designs. The logic is to recode the within-participants data in a between-subjects format (treating samples as unmatched) and to recoup the lost statistical power with adjustments to the error term. Experiments 1 and 2 were entered into one ANOVA and Experiments 3 and 4 into another, and the error variances from the two resulting $\mathrm{RCI} \times$ continuity contrasts were averaged to compute the error term; error degrees of freedom were computed by summing those of the two component error terms, weighted by the size of each term (Erlebacher, 1977). The effect term was computed by entering the results of all four experiments into an ANOVA with design (within participants vs. between participants) as a factor. The resulting RCI $\times$ continuity $X$ design interaction, which is of primary interest here, was reliable $\left[F(1,110)=4.1, p<.05, \eta^{2}=.05\right]$. The RCI $\times$ design interaction, computed analogously, was also reliable $\left[F(1,99)=10.4, p<.003, \eta^{2}=.11\right]$, but the continuity $\times$ design interaction was not $(F<1)$. Tests that did not involve interactions with design, which 
could therefore be computed with the usual error term, revealed main effects of RCI $[F(1,186)=6.67, p<.02$, $\left.\eta^{2}=.04\right]$ and continuity $[F(1,186)=173.1, p<.001$, $\left.\eta^{2}=.48\right]$, but not of design $(F<1)$, with no RCI $\times$ continuity interaction $(F<1)$.

In a comparison of Experiments 1 and 2, there were no effects of RCI $(F<1)$ or experiment $(p>.2)$, but there was an RCI $\times$ experiment interaction $[F(1,48)=7.9, p<$ $\left..008, \eta^{2}=.14\right]$ driven in part by an $87-\mathrm{msec}$ difference between the 100-msec RCI condition of Experiment 1 and that of Experiment 2 ( $p=.059$ for the simple effect of experiment on the $100-\mathrm{msec}$ RCI RTs). This is converging evidence that the system's response to one RCI depends in part on which other RCIs the system is exposed to. There was also an RCI $\times$ continuity interaction $\left[F(1,48)=18.3, p<.001, \eta^{2}=.275\right]$ and the usual effect of continuity $\left[F(1,48)=52.1, p<.001, \eta^{2}=.52\right]$, but no interactions of continuity $\times$ experiment $(F<1)$ or of $\mathrm{RCI} \times$ continuity $\times$ experiment $(p>.18)$.

In a comparison of Experiments 3 and 4, there was no effect of experiment $(p>.3)$ and no RCI $\times$ experiment interaction $(F<1)$, providing a check on the logic above; with the 100-msec RCI condition isolated from other RCI conditions, its RTs were similar in both Experiments 3 and 4, despite different amounts of practice (across different numbers of trials per session). There were effects of RCI $\left[F(1,86)=10.1, p<.003, \eta^{2}=.11\right]$ and continuity $\left[F(1,86)=76.4, p<.001, \eta^{2}=.47\right]$. There were no further interactions $(F \mathbf{s}<1)$.

\section{DISCUSSION}

The first question raised in the introduction concerned the generality of effects that have been attributed to dissipation of repetition priming (Meiran, Chorev, \& Sapir, 2000; Sohn \& Anderson, 2001). One would expect a passive process such as priming dissipation to be general enough to affect performance in a broad range of variants of a paradigm, but the RCI $\times$ continuity interactionthat is, the effect of RCI on switch cost-was absent in Experiments 3 and 4, suggesting that the effect has some other cause. The second question concerned a possible causal role of experimental design, and indeed the RCI $\times$ continuity interaction, like the CSI $\times$ continuity interaction in other studies (Altmann, 2004a, 2004b; Koch, 2001), seems to interact in turn with how RCI is manipulated: RCI and continuity interacted in Experiments 1 and 2, in which RCI was manipulated within participants, but not in Experiments 3 and 4, in which RCI was manipulated between participants. This suggests that the process behind the interaction is moderated by strategic variables.

Further evidence against a priming dissipation account of the RCI $\times$ continuity interaction is that this account predicts a specific trend for which the evidence from the present study is mixed. If repetition priming dissipates over time, then the reduction in switch cost at longer RCIs should be driven by an increase in repeat RT rather than by a decrease in switch RT. This was the case in Experiment 2, but in Experiment 1 the decrease was driven by faster switch RT (as also reported by Koch, 2001). Thus, even when RCI does affect switch cost, the pattern of changes in RT does not uniformly support the dissipation hypothesis.

One additional question is how to reconcile the absence of the RCI $\times$ continuity interaction in Experiments 3 and 4 with its presence in Koch (2001). One difference between the two studies that might be relevant is duration of the task cue: Koch's (2001) cue remained visible through the end of the trial, whereas cue offset in the present study was $100 \mathrm{msec}$ prior to stimulus onset. Consequently, the intervals between cue offset on one trial and cue onset on the next were much shorter in Koch's (2001) study (100 and $900 \mathrm{msec}$ ) than they were in the present study. With RT estimated at roughly $800 \mathrm{msec}$, offset-onset intervals here were roughly 1,000 and $1,700 \mathrm{msec}$ (Experiment 3 ) and 1,000 and 2,500 $\mathrm{msec}$ (Experiment 4). Priming dissipation might thus have gone undetected here if it began with cue offset and were especially rapid - as it might be, for instance, if it were linked to the contents of iconic memory, which presumably decay more between 100 and $900 \mathrm{msec}$ than between 1,000 and 1,700 or $2,500 \mathrm{msec}$. If iconic memory were the relevant difference between the present study and Koch (2001), as could perhaps be tested with a masking manipulation, this would place additional emphasis on the role of perceptual processes in task switching (Logan \& Bundesen, 2003; Mayr \& Kliegl, 2003).

A second additional question is how to explain a link between exposure to multiple RCIs and the RCI $\times$ continuity interaction. The present results suggest that priming is an unlikely explanation, but also that priming may not be the only process operating during the RCI. Another may be the task-independent preparatory process examined by Posner and Boies (1971), which produces peak phasic alertness about $500 \mathrm{msec}$ after a warning signal; performance declines sharply with shorter warning intervals and more gradually with longer ones. If onset of the RCI is viewed as a warning of sorts about the impending task cue, an 800-msec RCI would have been closer to optimal than either a 100 - or a 1,600-msec RCI in terms of its effect on cue-related processing. In accordance with this view, the 800-msec RCI in Experiment 3 led to faster responding than did the 100 -msec RCI, whereas the 1,600-msec RCI in Experiment 4 did not. In Experiments 1 and 2, in which RCI was randomized from trial to trial, it seems conceivable that the preparatory process behind the main effect in Experiment 3 could have responded in a way analogous to other preparatory processes when CSI is randomized (Altmann, 2004a). However, the details of how such processes might be affected by exposure to multiple RCIs and CSIs remain to be worked out, and they may emerge only from studies involving cognitive simulations (e.g., 
Sohn \& Anderson, 2003), in which the dynamics of such processes can be examined with the necessary precision.

In sum, these results suggest that, whether or not repetition priming causes switch cost, dissipation of such priming may not explain the $\mathrm{RCI} \times$ continuity interaction. Instead, the interaction might be explained by iconic memory, as is suggested by differences between the present method and that of Koch (2001), or by some complex effect of experimental design on phasic alertness, involving exposure to multiple levels of RCI. Specifying the precise mechanisms by which these or other factors (Luria \& Meiran, 2003) might cause RCI and continuity to interact will be a challenge for future research.

\section{REFERENCES}

Allport, A., \& Wylie, G. (2000). Task-switching, stimulus-response binding, and negative priming. In J. S. Driver (Ed.), Attention and performance XVIII: Control of cognitive processes (pp. 35-70). Cambridge, MA: MIT Press.

Altmann, E. M. (2004a). Advance preparation in task switching: What work is being done? Psychological Science, 15, 616-622.

Altmann, E. M. (2004b). The preparation effect in task switching: Carryover of SOA. Memory \& Cognition, 32, 153-163.

Buck-Gengler, C. J., \& Healy, A. F. (2001). Processes underlying long-term repetition priming in digit data entry. Journal of Experimental Psychology: Learning, Memory, \& Cognition, 27, 879-888.

Dreisbach, G., Haider, H., \& Kluwe, R. H. (2002). Preparatory processes in the task-switching paradigm: Evidence from the use of probability cues. Journal of Experimental Psychology: Learning, Memory, \& Cognition, 28, 468-483.

ERLEBACHER, A. (1977). Design and analysis of experiments contrasting the within- and between-subjects manipulation of the independent variable. Psychological Bulletin, 84, 212-219.

KeEle, S. W. (1969). Repetition effect: A memory-dependent process. Journal of Experimental Psychology, 80, 243-248.

Косн, I. (2001). Automatic and intentional activation of task sets. Journal of Experimental Psychology: Learning, Memory, \& Cognition, 27, 1474-1486.
KocH, I. (2005). Sequential task predictability in task switching. Psychonomic Bulletin \& Review, 12, 107-112.

LogAn, G. D., \& Bundesen, C. (2003). Clever homunculus: Is there an endogenous act of control in the explicit task-cuing procedure? Journal of Experimental Psychology: Human Perception \& Performance, 29, 575-599.

Luria, R., \& MeIRAN, N. (2003). Online order control in the psychological refractory period paradigm. Journal of Experimental Psychology: Human Perception \& Performance, 29, 556-574.

MAYR, U., \& KLIEGL, R. (2003). Differential effects of cue changes and task changes on task-set selection costs. Journal of Experimental Psychology: Learning, Memory, \& Cognition, 29, 362-372.

Meiran, N., Chorev, Z., \& SaPIR, A. (2000). Component processes in task switching. Cognitive Psychology, 41, 211-253.

Meiran, N., Levine, J., Meiran, N., \& Henik, A. (2000). Task set switching in schizophrenia. Neuropsychology, 14, 471-482.

Monsell, S. (2003). Task switching. Trends in Cognitive Sciences, 7, 134-140.

Posner, M. I., \& Boies, S. J. (1971). Components of attention. Psychological Review, 78, 391-408.

Poulton, E. C. (1982). Influential companions: Effects of one strategy on another in the within-subjects designs of cognitive psychology. Psychological Bulletin, 91, 673-690.

SoHn, M.-H., \& ANDERSON, J. R. (2001). Task preparation and task repetition: Two-component model of task switching. Journal of Experimental Psychology: General, 130, 764-778.

SoHn, M.-H., \& ANDERSON, J. R. (2003). Stimulus-related priming during task switching. Memory \& Cognition, 31, 775-780.

WaszaK, F., Hommel, B., \& Allport, A. (2003). Task-switching and long-term priming: Role of episodic stimulus-task bindings in taskshift costs. Cognitive Psychology, 46, 361-413.

\section{NOTE}

1. Including such "congruent" trials leaves the basic pattern of results intact; the RCI $\times$ continuity interaction in Experiment 1 and the $\mathrm{RCI} \times$ continuity $\times$ design interaction in the cross-experiment analysis become marginal ( $p=.066$ and $p=.063$, respectively), but no other trends or inferential statistics are affected.

(Manuscript received December 2, 2003; revision accepted for publication June 28, 2004.) 